\title{
Radiation effects on DNA content of cervical cancer cells: A rapid evaluation of radiation sensitivity by laser scanning cytometry
}

\author{
NAOKI FUJIYOSHI ${ }^{1,2}$, KIMIO USHIJIMA ${ }^{1}$, KOUICHIRO KAWANO ${ }^{1}$, KEIZO FUJIYOSHI ${ }^{1}$, \\ TOMOHIKO YAMAGUCHI ${ }^{3}$, YUKO ARAKI ${ }^{4}$, TATSUYUKI KAKUMA ${ }^{4}$, SUMIKO WATANABE $^{5}$, \\ TSUNEHISA KAKU ${ }^{5}$, TAKASHI NISHIDA ${ }^{2}$ and TOSHIHARU KAMURA ${ }^{1}$ \\ ${ }^{1}$ Department of Obstetrics and Gynecology, School of Medicine, Kurume University, Kurume, Fukuoka; \\ ${ }^{2}$ Department of Gynecology, Oita Prefecture Saiseikai Hita Hospital, Hita, Oita; ${ }^{3}$ Department of Diagnostic Pathology, \\ Kurume University Hospital; ${ }^{4}$ Department of Biostatistics, School of Medicine, Kurume University, Kurume; \\ ${ }^{5}$ Department of Health Science, Faculty of Medicine, Kyushu University, Higashi-ku, Fukuoka, Japan
}

Received January 16, 2014; Accepted August 13, 2014

DOI: $10.3892 / \mathrm{mco} .2014 .413$

\begin{abstract}
Since uterine cervical cancer is regarded as a radiosensive tumor, ionizing radiation is the most frequently used treatment modality against the disease. Although the crucial end-point is radiation-induced cell death, the tumors are not equally sensitive to radiation. Determining the criteria that may be used to predict tumor radiosensitivity is of importance; however, little success has been achieved thus far. In radioresistant cases the therapeutic strategy should be changed, thereby avoiding ineffective or unnecessary treatment. Furthermore, identification of the underlying molecular processes leading to radioresistance may lead to novel radiosensitising strategies. Cervical smears were obtained from seven patients with locally advanced cervical cancer following each radiotherapy, and the radiation-induced damage of cancer tissue was examined by routine cytology. Since the formation of DNA double-strand breaks is considered critical for the cytocidal effect of radiation therapy, the molecular changes of the neoplastic cells were also assessed by laser scanning cytometry (LSC). Radiation-induced morphological changes of cancer cells were evident at a dose of $7.2 \mathrm{~Gy}$, whereas increased DNA content (or DNA index) was observed prior to the onset of morphological changes. Molecular change was detected earlier than the morphological change of the irradiated cancer cells, indicating the feasibility of LSC in predicting the radiosensitivity of cervical cancer tissue.
\end{abstract}

Correspondence to: Dr Naoki Fujiyoshi, Department of Gynecology, Oita Prefecture Saiseikai Hita Hospital, 643-7 Oazamiwa, Hita, Oita 877-1292, Japan

E-mail: fujiyoshi_naoki@kurume-u.ac.jp

Key words: cervical cancer, radiosensitivity, laser scanning cytometry, DNA content, DNA index

\section{Introduction}

Uterine cervical cancer is the second most common type of cancer in females globally (1). According to the Globocan project, the disease has one of the greatest incidences of female mortalities, despite the effective screening system (2). Since cervical cancer is accepted as a radiosensitive tumor, ionizing radiation is the most frequently used treatment modality against the disease. Therefore, cellular radiosensitivity is a long-term research focus in the field of radiation oncology and biology as it has a clear effect on the outcome of therapy (3). The tumors, however, are not equally sensitive to radiation (4).

Traditionally, radioresistant tumors have been mainly designated from the histopathological view point (5). Glassy cell carcinoma and small cell carcinoma, including neuroendocrine tumors of the cervix, are generally regarded as radioresistant tumors. These specific histological types, however, are rather rare in cervical neoplasms. Furthermore, there may be significant variation in radiosensitivity even within the same histological type. Thus, tumor histology may not be a crucial determinant of radiosensitivity.

The initial damage should be a major determinant of cell radiosensitivity (6). By contrast, flow cytometry (FC) is a technique for the rapid analysis of DNA content, phenotype expression and the sorting of cells for further studies. FC allows quantitative measurements on single cells or cellular constituents at an extremely high speed rate. It is also feasible to monitor the effects of radiation on the cell cycle distribution following DNA staining of mammalian cells $(7,8)$. Since the formation of DNA double-strand breaks is considered to be critical for the cytocidal effect of radiation therapy (9-12), identifying the underlying molecular processes that results in radioresistance may lead to novel radiosensitising strategies.

A newly developed microscope-based laser scanning cytometer (LSC) offers a number of advantages over FC $(13,14)$. LSC can assess the DNA index (DI) in hypocellular materials, even on cytological smear slides (15). 
Table I. Characteristics of seven patients with inoperable cervical cancer.

\begin{tabular}{lccccccc}
\hline Patients & Age, years & FIGO stage & Tumor size, mm & Treatments & Clinical response & Prognosis & PFS, months \\
\hline 1 & 38 & IIIb & 59 & RT & PR & DOD & 7 \\
2 & 48 & IIIb & 68 & CCRT & CR & AWD & 24 \\
3 & 57 & IIIb & 59 & CCRT & PR & NED & - \\
4 & 53 & IIIb & 52 & CCRT & CR & NED & - \\
5 & 45 & IIIb & 32 & CCRT & PR & NED & - \\
6 & 70 & IIIb & 74 & CCRT & CR & DOD & 3 \\
7 & 74 & IVa & 50 & RT & CR & AWD & 24
\end{tabular}

FIGO, International Federation of Gynecology and Obstetrics; RT, radiation therapy; CCRT, concurrent chemoradiation therapy; CR, complete response; PR, partial response; DOD, died of disease; NED, no evidence of disease; AWD, alive with disease; PFS, progression-free survival.

Cell necrobiology incorporates the life processes associated with morphological, biochemical and molecular changes that predispose, precede and accompany cell death, and assess the consequences and tissue response to cell death (16). The aim of the present study was to discern the radiation-induced initial damage that leads to cancer cell death by necrobiological observation, including cytological morphology and LSC.

\section{Materials and methods}

Patients. Seven patients with locally advanced uterine cervical carcinoma were treated in the Kurume University Hospital (Kurume, Fukuoka, Japan) between June 2008 and June 2009. The patient characteristics are shown in Table I. Subsequent to obtaining informed consent, two patients received external beam radiotherapy alone at a dose of $1.8 \mathrm{~Gy}$ per day by linac $10 \mathrm{MeV}$ X-ray, and the remaining five patients underwent concurrent chemo-radiotherapy consisting of $5 \mathrm{mg} /$ body of cisplatin prior to the same dose of radiation therapy. A total dose of $50 \mathrm{~Gy}$ was administered. The patient age ranged from 38 to 74 years (mean, 58 years), and their tumors were classified as six stage IIIb diseases and one stage IVa cancer, according to the International Federation of Gynecology and Obstetrics staging criteria (17). The tumor histologies were equally non-keratinizing squamous cell carcinoma.

Preparation for the Papanicolau staining and DNA index. To exhibit the therapeutic responses, the response criteria offered by the UICC (Union Internationale Contre le Cancer) were used for the evaluable lesions (18). To assess the effects of radiation on tumor cells, cervical smears were obtained following each radiation therapy using a cotton-tipped stick, rinsed into serum-free medium (RPMI-1640) and fixed in 95\% ethanol prior to Papanicolau (Pap) staining. The radiation-induced morphological changes were evaluated by routine cytological examination.

For the cytometric observation, the Pap smear specimens were decolorized and dipped in propidium iodine (PI) solution, which was composed of $25 \mu \mathrm{g} / \mathrm{ml}$ PI in phosphate-buffered saline containing 0.1\% RNase (Sigma-Aldrich, St. Louis, MO, USA), and stained again with fluorochrome and PI. For the cellular DNA content analysis, a laser scanning cytometer

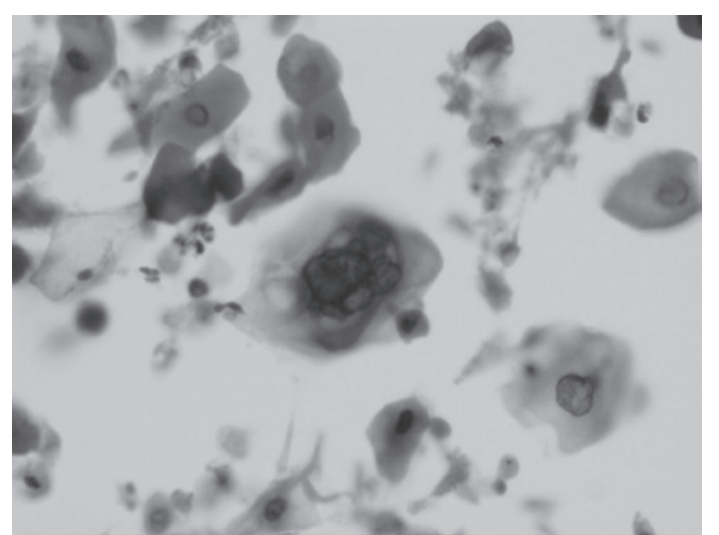

Figure 1. Radiation-induced morphological damage of cancer cells with cytoplasmic vacuolization (center). PAP stain; magnification, x400.

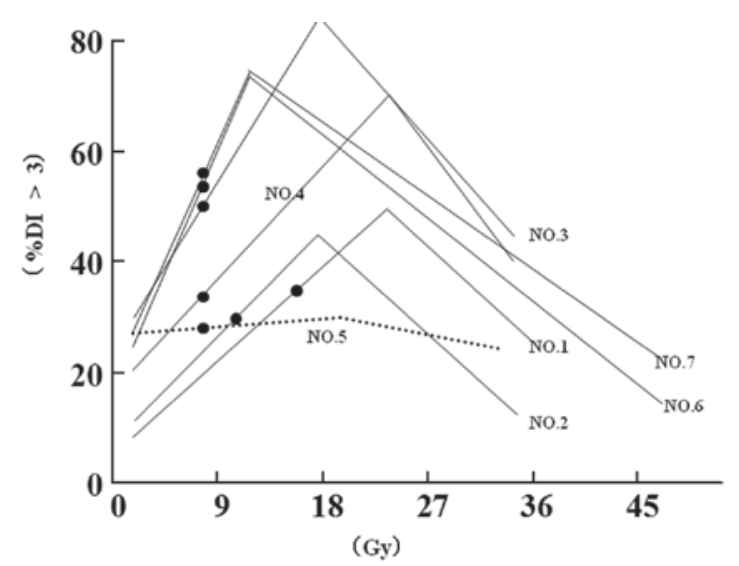

Figure 2. Linear spline graph of the change in DNA content, with the percentage of cells with a DI value $>3$ (y-axis) against the total radiation dose (x-axis). Other than the dotted line representing case No.5, a significant increase in DNA concentration was observed immediately following the start of irradiation. ${ }^{\bullet}$, onset of morphological changes in cervical cancer cells. DI, DNA index.

(LSC 101; Olympus Co., Tokyo, Japan) was used. At least 500 cancer cells were measured per sample.

To determine the DI, human leucocytes from freshly collected blood were used as a standard. A DI of 3.0 indicates DNA tetraploid. In the present study, tumors that were 
$3.0<\mathrm{DI}<30$ were classified as near-tetraploid cases and distinguished from DNA aneuploid tumors (DI $>3.0$ ). $\mathrm{P}<0.05$ was considered to indicate a statistically significant difference. All the patients provided written informed consent according to the institutional regulations. The study was approved by the Ethics Committee of the Department of Gynecology, Oita Prefecture Saiseikai Hita Hospital (Hita, Oita, Japan).

\section{Results}

Patient characteristics. Clinical responses to the radiation therapy are demonstrated in Table I, showing a response rate of $100 \%$ [four complete responses (CRs) and three partial responses (PRs)]. Three CR cases remained with no evidence of disease, and two PR cases remained with disease, showing a disease-free survival rate of $42.7 \%$.

Radiation-induced morphological damage of cancer cells with cytoplasmic vacuolization. In the cytology of all cases, a characteristic feature of the radiation effect was observed, exhibiting intracytoplasmic vacuolization (Fig. 1). These morphological changes emerged at cumulative doses between 7.2 and 14.4 Gy. Evidently, radiation that was $<7.2$ Gy did not cause any discernible changes in cancer cell cytology.

DNA content analysis. The DNA content analysis by LSC revealed six out of seven cases $(85.7 \%, \mathrm{P}<0.05)$, showing the percentage of cells having a DI value $>3$. The increase in DNA content was observed immediately following the start of radiation therapy, although the values were varied in each case (Fig. 2).

\section{Discussion}

Although ionizing radiotherapy is a key strategy and has $>80$ years history in the treatment of cervical cancer, the crucial determinant of radiosensitivity of the tumor remains unknown $(3,4,19)$. Thus, understanding how to identify the treatment-induced initial damage of cancer cells is essential for further therapeutic plans in cancer therapy. An assay with the ability to predict the radiosensitivity of tumors may provide a useful tool for the further individualization of radiotherapy of cancer patients (20). The prognostic significance of the fraction of survival following 2 Gy of radiation (SF2) is crucial in the treatment of head and neck cancer (21). However, the methods to determine SF2 can take $\leq 4$ weeks and are therefore not clinically practical.

To improve the treatment strategy, the early evaluation of therapeutic responses should be performed. The current response criteria, including that of the UICC, are only used for the evaluation of the treatment results. Radiation damages can be observed as cellular degeneration by cytology. However, these are late events in the treatment course. The importance of a more prompt evaluation is critical with regards to clinical decision making.

The impacts of radiation on cervical cancer cells resulted in a significant elevation of the DNA content level in six out of seven cases. Radiation causes a division delay dominated by $\mathrm{G} 2$ arrest in the cell cycle. The delay is likely a mechanism allowing the cell to repair its DNA damage. Ionizing radiation can also induce polyploidization in a cancer cell line (22).
Furthermore, radiation-induced apoptosis is morphologically identified by an increase in cytoplasmic granularity, chromatin condensation, membrane blebbing, cell shrinkage and the formation of distinctive nuclear bodies. These radiation effects should attribute to the change of DNA content.

Currently, there are a number of studies reporting on the concern of the radiation impacts on the molecular structure of cancer cells by novel techniques, including cytometry and LSC, revealing the precise mechanism involved in radiation effects. Despite the notable technical advance in elucidation of the molecular mechanism of the radiation effects, the results obtained remain to be utilized in clinical decision making. Rapid analyses of radiation-induced molecular changes by LSC are promising, although certain changes remain to be resolved, and this can lead to the 'real-time judgement' of the radiosensitivity of the tumor, and aid in making a treatment decision in the clinical practice.

\section{Acknowledgements}

The present study was supported by the Supporting Fund of Obstetrics and Gynecology of the Kurume University. The authors would like to thank C.T. Kazuko Eguchi for her technical support of Pap and PI staining.

\section{References}

1. Waqqoner SE: Cervical cancer. Lancet 361: 2217-2225, 2003.

2. Parkin DM, Bray F, Ferlay J and Pisani P: Estimating the world cancer burden: Globocan 2000. Int J Cancer 94: 153-156, 2001.

3. Hu Q and Hill RP: Radiosensitivity, apoptosis and repair of DNA double-strand breaks in radiation-sensitive Chinese hamster ovary cell mutants treated at different dose rates. Radiat Res 146: 636-645, 1996.

4. Weichselbaum RR, Dahleberg W and Little JB: Inherently radioresistant cells exist in some human tumors. Proc Natl Acad Sci USA 82: 4732-4735, 1985.

5. Steel GG, McMillan TJ and Peacock JH: The radiobiology of human cells and tissues. In vitro radiosensitivity. The picture has changed in the 1980s. Int J Radiat Biol 56: 525-537, 1989.

6. Ruiz de Almodóvar JM, Núñez MI, McMillan TJ, Olea C, Mort C, Villalobos M, Pedraza V and Steel GG: Initial radiation-induced DNA damage in human tumour cell lines: a correlation with intrinsic cellular radiosensitivity. Br J Cancer 69: 457-462, 1994.

7. Kamentsky LA and Melamed MR: Spectrophotometer cell sorter. Science 156: 1364-1365, 1967.

8. Baatout S and Derradji H: Cytometric methods to analyze radiation effects. J Biol Regul Homeost Agents 18: 101-105, 2004.

9. Ward JF: The yield of DNA double-strand breaks produced intracellulary by ionizing radiation: a review. Int J Radiat Biol 57: 1141-1150, 1990.

10. Brenner DJ and Ward JF: Constraints on energy deposition and target size of multiply damaged sites associated with DNA double-strand breaks. Int J Radiat Biol 61: 737-748, 1992.

11. Nikjoo H, O'Neill P, Wilson WE and Goodhead DT: Computational approach for determining the spectrum of DNA damage induced by ionizing radiation. Radiat Res 156: 577-583, 2001.

12. Datta K, Jaruga P, Dizdarglu M, Neumann RD and Winters TA: Molecular analysis of base damage clustering associated with a site-specific radiation-induced DNA double-strand break. Radiat Res 166: 767-781, 2006.

13. Kamentsky LA and Kamentsky LD: Microscope-based multiparameter laser scanning cytometer yielding data comparable to flow cytometry data. Cytometry 12: 381-387, 1991.

14. Kamentsky LA, Burger DE, Gershman RJ, Kamentsky LD and Luther E: Slide-based laser scanning cytometry. Acta Cytol 41: 123-143, 1997.

15. Martin-Reay DG, Kamentsky LA, Weinberg DS, Hollister KA and Cibas ES: Evaluation of a new slide-based laser scanning cytometer for DNA analysis of tumors. Comparison with flow cytometry and image analysis. Am J Clin Pathol 102: 432-438, 1994. 
16. Darzynkiewicz Z, Juan G, Li X, Gorczyca W, Murakami T and Traganos F: Cytometry in cell necrobiology: analysis of apoptosis and accidental cell death (necrosis). Cytometry 27: 1-20, 1997.

17. Petignat $P$ and Roy M: Diagnosis and management of cervical cancer. BMJ 335: 765-768, 2007.

18. Monfardini S, Brunner K, Crowther D, Olive D, MacDonald J, Eckhardt S and Whitehouse J (eds): Manual of Cancer Chemotherapy. 3rd edition. Union Internationale Contre le Cancer, Geneva 1981.

19. Gao Y, Ma JL and Song LP: The evaluation of older patients with cervical cancer. Clin Interv Aging 8: 783-788, 2013.

20. Bentzen SM and Hendry JH: Variability in the radiosensitivity of normal cells and tissues. Report from a workshop organised by the European Society for Therapeuic Radiology and Oncology in Edinburgh, UK, 19 September 1998. Int J Radiat Biol 75: 513-517, 1999.
21. Björk-Eriksson T, West C, Karlsson E and Mercke C: Tumor radiosensitivity (SF2) is a prognostic factor local control in head and neck cancers. Int J Radiat Oncol Biol Phys 46: 13-19, 2000.

22. Baatout S, Derradji H, Jacquet P, Ooms D, Michaux A and Mergeay M: Enhanced radiation-induced apoptosis of cancer cell lines after treatment with resveratrol. Int J Mol Med 13: 895-902, 2004. 